\title{
Reduction in renal blood flow following acute increase in the portal pressure: evidence for the existence of a hepatorenal reflex in man?
}

\author{
R Jalan, E H Forrest, D N Redhead, J F Dillon, P C Hayes
}

\begin{abstract}
Background-To investigate the relation between changes in portal haemodynamics and renal blood flow (RBF) in patients with cirrhosis.

Patients/Methods-Twenty patients with cirrhosis and transjugular intrahepatic portosystemic stent-shunts were divided into two groups which were well matched. At routine portography, either changes in unilateral RBF (group I) or changes in cardiac output (group II) before and after shunt occlusion were studied. Blood was obtained from the renal and systemic circulations for the measurement of neurohumoral factors before and after shunt occlusion in group I patients.

Results-After shunt occlusion, there was a progressive reduction in unilateral RBF from a mean (SD) of 289 (32) to 155 (25) $(-43 \cdot 5 \%)(p<0 \cdot 001)$. These changes correlated significantly with the changes in the portal atrial gradient $(p<0 \cdot 001)$. There was no significant change in heart rate, mean arterial pressure and right atrial pressure. No significant changes were found in the concentrations of the various neurohumoral factors measured. There was a less notable but significant reduction in the cardiac output $(-10.9 \%) \quad(p=0.02)$ unaccompanied by significant reduction in the pulmonary capillary wedge pressure or mean arterial pressure.

Conclusions-These results suggest the existence of hepatorenal reflex in man which is important in the regulation of RBF, although other mechanisms may also be contributory.

(Gut 1997; 40: 664-670)
\end{abstract}

Keywords: cirrhosis, hepatorenal reflex, portal pressure, TIPS, renal blood flow, ascites.

Medicine

Royal Infirmary of

Edinburgh,

Edinburgh

R Jalan

E H Forrest

JF Dillon

P C Hayes

Department of

Radiology

D N Redhead

Correspondence to:

Dr Rajiv Jalan,

Department of Medicine,

Royal Infirmary of

Edinburgh,

Edinburgh,

Edinburgh EH3 9YW.

Accepted for publication

28 January 1996

Cirrhosis and portal hypertension are characterised by an increase in splanchnic circulation, peripheral vasodilatation and a spectrum of renal abnormalities, manifested in its mildest form by sodium retention and ascites, and in the severe form by the hepatorenal syndrome. The characteristic findings in the renal dysfunction of cirrhosis are a reduction in renal blood flow (RBF) and an increase in renal resistance. ${ }^{12}$ The reduction in $R B F$ is accompanied by redistribution of intrarenal blood flow from the cortex to the medulla, even in patients without ascites, ${ }^{3}$ and the hepatorenal syndrome is also characterised by constriction of the intralobular and the arcuate arteries. ${ }^{4}$

There is considerable evidence of increased sympathetic nervous activity in patients with cirrhosis and sodium retention. Noradrenaline concentrations reflect sympathetic nervous activity and its concentration in the circulation is a result of overproduction rather than reduced clearance. ${ }^{5}$ Concentrations of noradrenaline are inversely related to sodium excretion. ${ }^{6}$ Lang $e t a l,{ }^{7}$ in an animal model, found an acute reduction in $R B F$ following infusion of glutamine into the portal vein. The effect of the infusion was to induce acute hepatocyte swelling and portal hypertension. This was abolished following section of the hepatic vagal fibres and renal denervation. They proposed the existence of a hepatorenal axis controlled by a reflex arc, the afferent limb of which was the hepatic vagal innervation and the efferent limb was the renal sympathetic system.

Transjugular intrahepatic portosystemic stent-shunt (TIPSS) is an interventional radiological technique that involves the creation of a fistulous communication between the hepatic and portal veins through the liver parenchyma; this track is supported by an expandable metal stent. TIPSS has been shown to reduce portal hypertension and is effective in controlling variceal haemorrhage and ascites. ${ }^{89}$ Routine portography is performed to ensure adequate shunt function and this involves direct cannulation of the shunt. The shunt can be occluded using an angioplasty balloon, producing a large increase in the portal atrial gradient (PAG) (portal pressure - right atrial pressure). The aim of this study was to investigate the relation between changes in portal haemodynamics and renal blood flow in patients with cirrhosis.

\section{Methods}

The study was approved by the local ethics committee and the patients studied gave their informed consent. They were divided into two groups which were studied consecutively Changes following shunt occlusion were measured either in RBF (group I) or in cardiovascular haemodynamics (group II).

PATIENTS

Patients in the two groups were well matched for age, sex, and aetiology and severity of liver disease. All patients had undergone TIPSS for 
recurrent variceal haemorrhage, one to four months previously. They were recruited into the study when they were attending for portography for the assessment of shunt function. None of the patients had ascites and none were taking diuretics for at least seven days before the study. They had no biochemical evidence of renal failure and their sodium intake was limited to $100 \mathrm{mmol} /$ day. They were included in the study only if they had no signs of shunt insufficiency at the time of portography which was defined as a portal pressure gradient (portal pressure - inferior vena caval pressure) of less than $12 \mathrm{~mm} \mathrm{Hg}$. Table I summarises patient details.

\section{PORTOGRAPHY}

Assessment of shunt function involved the catheterisation of the shunt via the internal jugular route using midazolam for sedation. After portography to outline the portal system and the shunt, pressure was recorded (Hewlett-Packard, USA) in the portal vein, the inferior vena cava and the right atrium, and the portal pressure and the PAG were calculated. Unilateral $R B F$, renal vein pressure, portal vein flow, and blood were sampled from patients in group I. Cardiac haemodynamics were studied in patients in group II. Table II outlines the other variables measured.
MEASUREMENT OF PORTAL VEIN FLOW

After the pressure measurements, the sheath was introduced through the shunt and a double thermister catheter (Webster Laboratories, California, USA) positioned in the portal vein. The distal end of this catheter was placed under fluoroscopic control in the portal vein just distal to the junction of the superior mesenteric and splenic veins. The protocol that was used for the measurement of changes in the portal and renal blood flow has been well validated by our group both in vitro and in vivo. ${ }^{10}$ Briefly, the injectate used was $5 \%$ dextrose (at room temperature, about $22^{\circ} \mathrm{C}$ ). This was infused at $50 \mathrm{ml} / \mathrm{min}$ using a syringe pump (Harvard model 22, modified to meet BS 5724 standard). The signals from the internal (injectate) and external (mixed blood) thermistors (distance $2.4 \mathrm{~cm}$ ) were transferred through a custom built interface (isolated to BS 5724 type CF) and processed in an IBM compatible PS2-286 microcomputer system. This provided a real time graphic display of blood flow. Collection of data was started and stopped as required at the different stages of the test. Mean blood flow was measured over 20 seconds. Specific events were designated using on screen markers. Data were stored on floppy disks for analysis at a later time.

MEASUREMENT OF CHANGES IN RENAL BLOOD FLOW

Changes in unilateral RBF were measured in patients in group $\mathrm{I}$. The catheter was replaced by an angioplasty balloon which was positioned in the intrahepatic portion (Fig 1) of the shunt. The sheath was positioned in the right atrium and the side arm used to measure the right atrial pressure. Electrocardiogram and pulse rate were monitored continuously. Mean arterial pressure was recorded non-invasively every two minutes. A double thermistor catheter was introduced through a sheath in the right femoral vein into the right renal vein and the changes in $R B F$ and renal vein pressure continuously recorded as described earlier for measurement of portal vein flow. The right renal vein was chosen, firstly, because the left renal vein also drains the suprarenal glands which would complicate both sampling of blood and measurement of blood flow and, secondly, because cannulation of the right renal vein was a lot easier from the femoral vein as it follows the natural curvature of the catheter. Changes in the portal pressure were recorded through the central lumen of the angioplasty balloon. The coefficient of variation in $\mathrm{RBF}$ using this catheter was $7 \cdot 8 \%$.

After measurements at baseline, the angioplasty balloon was inflated and the changes in $\mathrm{RBF}$ and other variables as outlined earlier were recorded at two minute intervals for 12 minutes. The balloon was then deflated and variables measured for four minutes at two minute intervals. Renal vein resistance was calculated as the ratio of the RBF to renal vein pressure. 


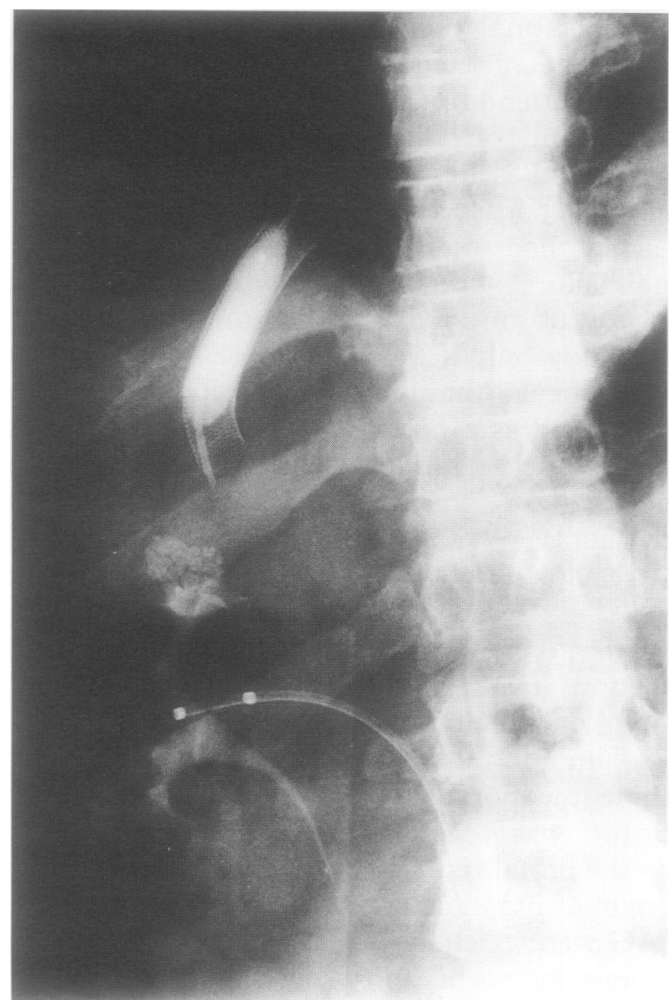

Figure 1: $\mathrm{x}-$ Ray film showing an inflated angioplasty balloon in the shunt inserted through the internal jugular vein and a reverse thermodilution catheter in the right renal vein inserted through the femoral vein.

MEASUREMENT OF CARDIAC HAEMODYNAMICS Changes in cardiac haemodynamics were measured in patients in group II. The outline of the procedure was similar to that used for the measurement of RBF. A Swan-Ganz catheter was introduced through a sheath in the femoral vein into the pulmonary artery and changes in cardiac output, systemic vascular resistance and pulmonary capillary wedge pressure recorded before and six and 12 minutes after shunt occlusion and after balloon deflation. Three separate recordings were made and the average of these was recorded.

BLOOD SAMPLING AND HORMONAL ASSAYS

Plasma was collected from the right atrium and the renal vein, respectively, before and 12 minutes after shunt occlusion and stored at $-70^{\circ} \mathrm{C}$ for analysis at a later date. Although the pulmonary artery would have been ideal for sampling to prevent the effects of streaming and inadequate mixing of blood, the right atrium was chosen because it was thought unethical to introduce another catheter into the pulmonary artery.

Plasma was also collected from a peripherally sited cannula from 12 (eight men) healthy volunteers with a mean (SD) age of $51.3(4 \cdot 2)$ years who were maintained on a diet containing $80-100 \mathrm{mmol} / \mathrm{l}$ sodium for one week.

Measurement of plasma renin activity (PRA)

This radioimmunoassay was based on the principle that angiotensin $I$ is generated by the action of renin on its substrate angio- tensinogen. An in-house antibody for angiotensin I was used. Coefficient of variation for the assay was $5 \cdot 2 \%$. Normal range for PRA was $1.6( \pm 1 \cdot 5) \mathrm{ng} / \mathrm{ml} /$ hour for patients on $80-100$ $\mathrm{mmol} / \mathrm{l}$ sodium (no added salt diet).

\section{Measurement of angiotensin II}

Samples of blood were obtained in angiotensin II inhibitor. Angiotensin II values were measured by radioimmunoassay with an inhouse rabbit antibody R6B4. Coefficient of variation for the assay was $3 \cdot 2 \%$. Normal range for angiotensin II was $0.032( \pm 0 \cdot 01) \mathrm{ng} / \mathrm{ml}$.

Measurement of atrial natriuretic peptide (ANP) The radioimmunoassay was performed using an antibody to human ANP that had been raised in rabbit after immunisation with human ANP. Coefficient of variation for the assay was $9 \cdot 8 \%$. Normal range for ANP was 52.3 (range $0-100) \mathrm{pg} / \mathrm{ml}$.

\section{Measurement of cyclic guanosine monophosphate (cGMP)}

Dried samples were acetylated and the plasma cGMP values measured with an in-house antibody (ED2-3). Coefficient of variation for the assay was $3.6 \%$. Normal range of cGMP was $1 \cdot 18( \pm 0 \cdot 34) \mathrm{nmol} / 1$.

\section{Measurement of adrenaline and noradrenaline}

Extracted samples were assayed using high performance liquid chromatography and electrochemical detection. ${ }^{11}$ Coefficients of variation were less than $10 \%$ and the normal values for adrenaline and noradrenaline were less than 0.4 and $5 \mathrm{nmol} / 1$, respectively.

\section{STATISTICAL ANALYSIS}

Results are expressed as mean (SD) unless otherwise specified. Differences between groups were calculated using the unpaired $t$ test. The relations between variables were calculated using linear regression. The method of summary measures, as described by Matthews et al, ${ }^{12}$ was used to analyse the data. Briefly, a summary of the response (that is, the rate of change in renal blood flow, cardiac output (Figs 2 and 3), arterial blood pressure, right atrial pressure, etc.) was calculated for every patient. The second stage was to analyse the summary measure using a simple statistical technique such the paired $t$ test comparing the baseline value with the value at 12 minutes which was the point of maximal change.

\section{Results}

PAG AND PORTAL VEIN BLOOD FLOW

The mean (SD) internal diameter of the shunt was $9.4(1.3) \mathrm{mm}$ and the mean PAG was 8.3 $(0 \cdot 7) \mathrm{mm} \mathrm{Hg}$, representing an adequate shunt. After shunt occlusion, the PAG increased to 50 (3.3) $\mathrm{mm} \mathrm{Hg}$. After deflation of the balloon, 


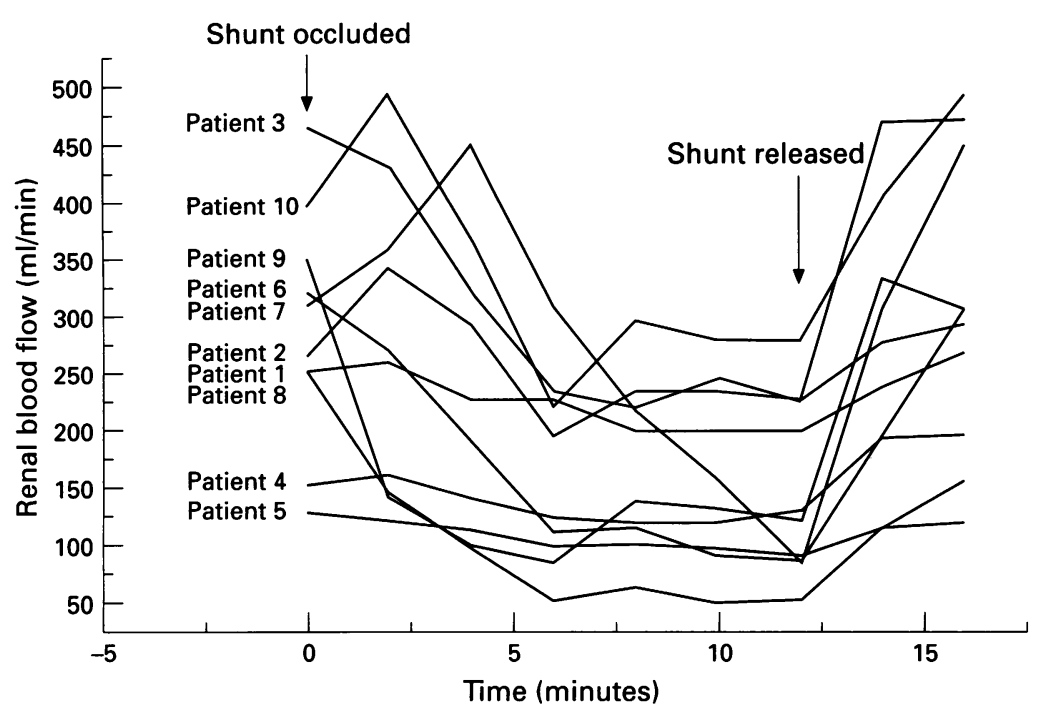

Figure 2: Changes in the unilateral renal blood flow before and after shunt occlusion.

the PAG was $8 \cdot 1(0.6) \mathrm{mm} \mathrm{Hg}$. Portal vein blood flow at rest was $482(201 \cdot 6) \mathrm{ml} / \mathrm{min}$. No significant correlation was found between portal vein flow and the portal pressure gradient $(r=0 \cdot 3, p=0 \cdot 4)$. Resting $R B F$ was 289 $(102.6) \mathrm{ml} / \mathrm{min}$ and this correlated inversely with portal vein blood flow $(r=-0.73, \mathrm{p}<0.02)$.

CHANGES IN RBF

After shunt occlusion, there was a progressive reduction in RBF ( $p<0.001)$ which was most noticeable at 12 minutes (Fig 2; Table III). Mean change was $-133.8(89) \mathrm{ml} / \mathrm{min}(-43.5$ $(25 \cdot 3) \%$. After balloon deflation, the RBF returned to baseline values over a period of four minutes. Shunt occlusion was associated with a significant increase in the PAG from a mean of $8.3(2 \cdot 1)$ to $50.6(10 \cdot 5) \mathrm{mm} \mathrm{Hg}$ $(\mathrm{p}<0.0001)$. The change in RBF correlated significantly with the change in PAG $(r=-0 \cdot 85$, $\mathrm{p}<0.001$ ).

Renal vein pressure decreased significantly following shunt occlusion $(-26(17 \cdot 2) \%)$ $(\mathrm{p}<0 \cdot 01)$. Although there was a mild reduction in heart rate $(-6.3(7 \cdot 4) / \mathrm{min},-7 \cdot 8(9.5) \%)$, mean arterial pressure $(-10.3(9.4) \mathrm{mm} \mathrm{Hg}$,

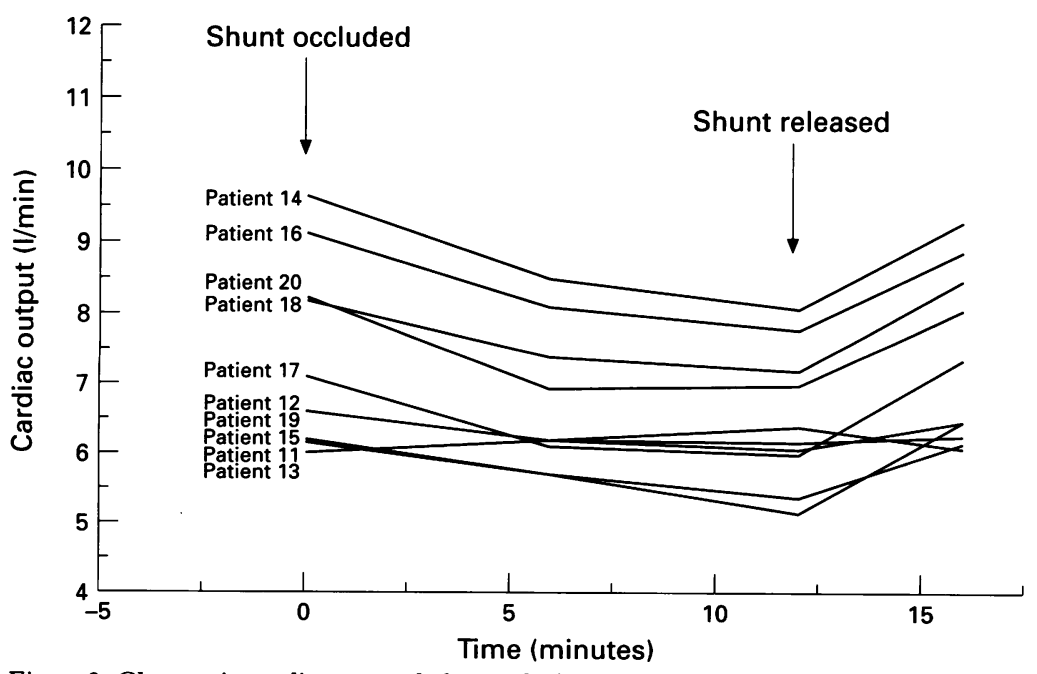

Figure 3: Changes in cardiac output before and after shunt occlusion.
$-9 \cdot 7(8 \cdot 6) \%)$, and right atrial pressure $(-0.3$ $(1 \cdot 7) \mathrm{mm} \mathrm{Hg},-21.3(74 \cdot 2) \%)$, these changes were not statistically significant (Table III). Significant correlation was observed between changes in renal blood flow and the change in renal vascular resistance $(r=-0 \cdot 88, p<0 \cdot 0005)$.

CHANGES IN CARDIAC HAEMODYNAMICS

Cardiac output was reduced from a mean of $7 \cdot 4(1 \cdot 3) 1 / \mathrm{min}$ before shunt occlusion to 6.5 (1) $1 /$ min 12 minutes after shunt occlusion $(p=0 \cdot 02)$. This returned to pre-occlusion values after balloon deflation (Fig 3) (Table IV). Mean change was $-0.85(0.55) 1 / \min (-10.9$ $(6 \cdot 9) \%)$. Shunt occlusion was associated with a significant increase in the PAG $(\mathrm{p}<0.0001)$. This was not associated with any significant change in the heart rate, mean arterial pressure or right atrial pressure. Shunt occlusion was associated with an insignificant reduction in the pulmonary capillary wedge pressure $(p=0.06)$. Systemic vascular resistance (SVR) increased significantly from $1128(270 \cdot 6)$ to 1347 (356.4) dyne sec/cm ${ }^{5}(\mathrm{p}=0.02)$. There was, however, no significant correlation between the changes in the SVR and the changes in the cardiac output $(r=0.4, \mathrm{p}=0.24)$. The change in cardiac output was also independent of the changes in the PAG $(r=0 \cdot 5, \mathrm{p}=0 \cdot 09)$.

CHANGES IN THE NEUROHORMONAL PROFILE Blood for the measurement of neurohormonal factors was obtained from group I patients. Concentrations of the different factors in the renal and systemic circulation before and after shunt occlusion are summarised in Table V. Systemic concentrations of PRA, angiotensin II, and cGMP were significantly higher in the patients compared with controls $(p<0.04$, $\mathrm{p}<0.02$ and $\mathrm{p}<0.01$, respectively). There was no significant difference in the adrenaline, noradrenaline, and ANP concentrations in the patients compared with age and sex matched healthy volunteers.

Concentrations of cGMP and noradrenaline were significantly higher in the renal compared with the systemic circulation $(p<0.01$ and $\mathrm{p}<0.02$, respectively). PRA was significantly lower $(p<0.04)$ and there was no significant difference in the concentrations of angiotensin II, ANP and adrenaline in the systemic and the renal circulations. After shunt occlusion, there was no significant change in the concentration of any of these variables in the systemic or the renal circulations.

\section{Discussion}

This study shows that there is a dramatic reduction in RBF after acute increase in the PAG. This change is not related to alteration in the mean arterial pressure, heart rate or the right atrial pressure. The relation between changes in RBF and cardiac output would ideally have been studied in the same patient but the introduction of a third line for central venous access was thought to be unethical. Although changes in cardiac output $(-10.9$ 
TABLE III Changes in renal blood flow after acute shunt occlusion

\begin{tabular}{|c|c|c|c|c|c|c|c|c|c|c|c|c|}
\hline \multirow{2}{*}{$\begin{array}{l}\text { Patient } \\
\text { number }\end{array}$} & \multicolumn{2}{|c|}{$\begin{array}{l}\text { Renal blood flow } \\
(\mathrm{ml} / \mathrm{min})\end{array}$} & \multicolumn{2}{|c|}{$\begin{array}{l}\text { Renal vein } \\
\text { pressure } \\
(\text { mm } \mathrm{Hg})\end{array}$} & \multicolumn{2}{|c|}{ Heart rate (/min) } & \multicolumn{2}{|c|}{$\begin{array}{l}\text { Mean arterial } \\
\text { pressure }(\mathrm{mm} \mathrm{Hg})\end{array}$} & \multicolumn{2}{|c|}{$\begin{array}{l}\text { Right arterial } \\
\text { pressure }(\mathrm{mm} \mathrm{Hg})\end{array}$} & \multicolumn{2}{|c|}{$\begin{array}{l}\text { Porto-atrial } \\
\text { gradient } \\
\text { (mm } \mathrm{Hg})\end{array}$} \\
\hline & Before & After & Before & After & Before & After & Before & After & Before & After & Before & After \\
\hline $\begin{array}{l}1 \\
2 \\
3 \\
4 \\
5 \\
6 \\
7 \\
8 \\
9 \\
10 \\
\text { Mean change } \\
\text { \% change } \\
\text { p Value }\end{array}$ & $\begin{array}{l}254 \\
265 \\
464 \\
153 \\
128 \\
320 \\
310 \\
251 \\
351 \\
395 \\
-133 \cdot 8 \\
-43 \cdot 5 \\
<0.0\end{array}$ & $\begin{array}{r}200 \\
235 \\
247 \\
121 \\
98 \\
91 \\
87 \\
53 \\
140 \\
281 \\
39) \\
5 \cdot 3) \\
\end{array}$ & $\begin{array}{r}4 \\
1 \\
11 \\
8 \\
5 \\
8 \\
11 \\
0 \\
7 \\
8 \\
-2(1 \\
-26(1 \\
<0.0\end{array}$ & $\begin{array}{r}2 \\
1 \\
8 \\
7 \\
3 \\
6 \\
8 \\
-1 \\
4 \\
5 \\
\end{array}$ & $\begin{array}{l}75 \\
99 \\
72 \\
76 \\
89 \\
70 \\
93 \\
74 \\
88 \\
64 \\
-6 \cdot 3( \\
-7 \cdot 8( \\
0 \cdot 07\end{array}$ & $\begin{array}{l}77 \\
95 \\
70 \\
69 \\
82 \\
52 \\
88 \\
76 \\
68 \\
60 \\
\\
\text { S) }\end{array}$ & $\begin{array}{c}98 \\
94 \\
99 \\
107 \\
107 \\
77 \\
102 \\
92 \\
77 \\
110 \\
-10 \cdot 3 \\
-9 \cdot 7 \\
0.07\end{array}$ & $\begin{array}{r}94 \\
94 \\
94 \\
97 \\
99 \\
78 \\
96 \\
89 \\
85 \\
116 \\
4) \\
6) \\
\text { NS) }\end{array}$ & $\begin{array}{r}3 \\
-3 \\
3 \\
6 \\
1 \\
6 \\
6 \\
-3 \\
0 \\
7 \\
-0.3( \\
-21.3( \\
0.59\end{array}$ & $\begin{array}{r}4 \\
-4 \\
5 \\
7 \\
-1 \\
5 \\
4 \\
-1 \\
0 \\
5 \\
7) \\
7 \cdot 2) \\
\text { NS) }\end{array}$ & $\begin{array}{c}8 \\
10 \\
11 \\
12 \\
7 \\
6 \\
6 \\
9 \\
8 \\
6 \\
42 \cdot 3 \\
561(2 \\
<0.00\end{array}$ & $\begin{array}{l}36 \\
44 \\
53 \\
35 \\
45 \\
67 \\
58 \\
60 \\
58 \\
50 \\
1 \cdot 7) \\
7 \\
1\end{array}$ \\
\hline
\end{tabular}

Before and after values refer to the maximum change ( 12 minutes) in the variables measured. Results expressed as mean (SD). $\mathrm{p}$ Values were measured using the paired $t$ test.

TABLE IV Changes in cardiac output after acute shunt occlusion

\begin{tabular}{|c|c|c|c|c|c|c|c|c|c|c|}
\hline \multirow{2}{*}{$\begin{array}{l}\text { Patient } \\
\text { number }\end{array}$} & \multicolumn{2}{|c|}{$\begin{array}{l}\text { Cardiac output } \\
\text { (U/min) }\end{array}$} & \multicolumn{2}{|c|}{$\begin{array}{l}\text { Right arterial } \\
\text { pressure }(\mathrm{mm} \mathrm{Hg})\end{array}$} & \multicolumn{2}{|c|}{$P C W P(\mathrm{~mm} \mathrm{Hg})$} & \multicolumn{2}{|c|}{ SVR (dyne sec/cm $)$} & \multicolumn{2}{|c|}{$\begin{array}{l}\text { Porto-atrial } \\
\text { gradient }(\mathrm{mm} \mathrm{Hg})\end{array}$} \\
\hline & Before & After & Before & After & Before & After & Before & After & Before & After \\
\hline $\begin{array}{l}11 \\
12 \\
13 \\
14 \\
15 \\
16 \\
17 \\
18 \\
19 \\
20 \\
\text { Mean change } \\
\text { \% change } \\
\text { p Value }\end{array}$ & $\begin{array}{l}6 \cdot 2 \\
6 \cdot 6 \\
6 \\
9 \cdot 6 \\
6 \cdot 2 \\
9 \cdot 2 \\
7 \cdot 1 \\
8 \cdot 2 \\
8 \cdot 2 \\
6 \cdot 6 \\
-0 \cdot 85 \\
-10 \cdot 9 \\
0 \cdot 02\end{array}$ & $\begin{array}{l}5 \cdot 4 \\
6 \cdot 1 \\
6 \cdot 4 \\
8 \cdot 1 \\
5 \cdot 2 \\
7 \cdot 8 \\
6 \\
7 \\
7 \cdot 2 \\
6 \cdot 2 \\
55)\end{array}$ & $\begin{array}{c}7 \\
0 \\
2 \\
8 \\
-4 \\
8 \\
10 \\
6 \\
10 \\
0 \\
-1 \cdot 7( \\
-39 \cdot 1( \\
0 \cdot 08\end{array}$ & $\begin{array}{r}4 \\
1 \\
-2 \\
7 \\
-1 \\
5 \\
4 \\
4 \\
7 \\
1\end{array}$ & $\begin{array}{r}9 \\
17 \\
20 \\
8 \\
-9 \\
17 \\
16 \\
7 \\
11 \\
17 \\
-3 \cdot 7 \\
-43 \cdot 4 \\
0.06\end{array}$ & $\begin{array}{r}1 \\
14 \\
27 \\
5 \\
-5 \\
9 \\
6 \\
0 \\
5 \\
14 \\
3) \\
\text { S) }\end{array}$ & $\begin{array}{c}1025 \\
1321 \\
1176 \\
834 \\
1210 \\
804 \\
1669 \\
1009 \\
890 \\
1345 \\
219(2 \\
20.4 \\
0.02\end{array}$ & $\begin{array}{r}1197 \\
1412 \\
1131 \\
946 \\
2052 \\
1010 \\
1843 \\
1333 \\
1131 \\
1421 \\
\end{array}$ & $\begin{array}{l}9 \\
7 \\
7 \\
5 \\
6 \\
8 \\
6 \\
6 \\
8 \\
7 \\
44 \cdot 9 \\
680(2 \\
<0.00\end{array}$ & $\begin{array}{l}42 \\
45 \\
44 \\
61 \\
54 \\
43 \\
59 \\
59 \\
64 \\
46\end{array}$ \\
\hline
\end{tabular}

Before and after values refer to the maximum change (12 minutes) in the variables measured. Results expressed as mean (SD). $\mathrm{p}$ Values were measured using the paired $t$ test. PCWP=pulmonary capillary wedge pressure.

$(6 \cdot 9) \%)$ were statistically significant, this change was not sufficient to explain the magnitude of the change in RBF (-43.5 (25.3)\%). Furthermore, the changes in cardiac output were not associated with any significant disturbance in the mean arterial pressure which is of paramount importance in the perfusion of the kidneys.

Several theories regarding the initiation of renal vasoconstriction in cirrhosis have been proposed. The underfill hypothesis ${ }^{13}$ gave way to the overfill hypothesis, ${ }^{14}$ which has been replaced by the peripheral vasodilatation theory. ${ }^{15}$ According to this theory, the initiating event is splanchnic vasodilatation and portal hypertension produced by the action of splanchnic vasodilators upon the portal and systemic circulation as a result of reduced

TABLE V Changes in neurohormonal factors after shunt occlusion

\begin{tabular}{|c|c|c|c|c|}
\hline \multirow[b]{2}{*}{ Variable } & \multicolumn{2}{|l|}{ Before occlusion } & \multicolumn{2}{|l|}{ After occlusion } \\
\hline & Renal & Systemic & Renal & Systemic \\
\hline $\begin{array}{l}\text { Renal blood flow (ml/min) } \\
\text { Portal pressure gradient }(\mathrm{mm} \mathrm{Hg}) \\
\text { Plasma renin activity }(\mathrm{ng} / \mathrm{ml} / \mathrm{hr}) \\
\text { ANP }(\mathrm{pg} / \mathrm{ml}) \\
\text { Angiotensin II }(\mathrm{ng} / \mathrm{ml}) \\
\text { cGMP (nmol/l) } \\
\text { Adrenaline (nmol/l) } \\
\text { Noradrenaline (nmol/l) }\end{array}$ & $\begin{array}{l}289(32)^{\star \star \star} \\
8 \cdot 3(0 \cdot 7)^{\star \star \star} \\
3 \cdot 5(0 \cdot 7) \\
103(42) \\
0 \cdot 13(0 \cdot 1) \\
3 \cdot 2(0 \cdot 5) \\
0 \cdot 3(0 \cdot 1) \\
5 \cdot 7(0 \cdot 7)\end{array}$ & $\begin{array}{c}4 \cdot 1(0 \cdot 8) \\
49 \cdot 2(22) \\
0.02(0) \\
1.2(0 \cdot 2) \\
0.3(0 \cdot 1) \\
4.8(0 \cdot 7)\end{array}$ & $\begin{array}{l}155(25)^{\star \star \star} \\
50 \cdot 6(3 \cdot 3)^{\star \star \star} \\
3.9(0 \cdot 8) \\
65 \cdot 6(11 \cdot 4) \\
0 \cdot 15(0 \cdot 13) \\
2 \cdot 8(0 \cdot 3) \\
0.4(0 \cdot 2) \\
5 \cdot 9(1 \cdot 1)\end{array}$ & $\begin{array}{l}4 \cdot 8(0.8) \\
33(14) \\
0.03(0.01) \\
1(0.23) \\
0.5(0.3) \\
4.9(1)\end{array}$ \\
\hline
\end{tabular}

Results are expressed as mean (SEM)

$\star \star \star \star \mathrm{p}<0.001$ (paired $t$ test).

Renal and systemic refer to the site of blood sampling. clearance and shunting of these substances from the portal to systemic circulation through the collaterals. This causes relative underfilling of the arterial vascular compartment, thereby activating compensatory mechanisms which are responsible for reduction in renal blood flow and sodium retention.

RBF is regulated by intrarenal, hormonal and neural factors. The intrarenal factors that have been implicated include the kallikreinkinin system, ${ }^{16}$ prostaglandins, ${ }^{17}$ thromboxane, ${ }^{17}$ leukotrienes, ${ }^{18}$ platelet activating factor, ${ }^{19}$ endothelin, ${ }^{20}$ nitric oxide, ${ }^{21}$ and adenosine. ${ }^{22}$ Hormonal factors that are closely related to sodium retention include changes in the renin-aldosterone-angiotensin axis, ${ }^{23}$ antidiuretic hormone ${ }^{24}$ and the atrial natriuretic peptide. $^{25}$

The kidneys are innervated by sympathetic nerves derived from $\mathrm{T} 11, \mathrm{~T} 12$ and $\mathrm{L} 1$ via the coeliac and the aortorenal ganglia. These are distributed both to the renal microvasculature and to the different parts of the nephron. ${ }^{26}$ Stimulation of the sympathetic system produces an increase in the renal vascular resistance thereby reducing $\mathrm{RBF}^{27}{ }^{28}$ The importance of lumbar sympathetic discharge in the pathogenesis of the hepatorenal syndrome is reflected by notable improvement in effective plasma flow after sympathectomy. ${ }^{29}$ The inverse relation between portal vein flow and $R B F$, and the reduction in RBF with acute increase in PAG and renal resistance suggests 
the existence of a signalling mechanism between the liver and the kidney.

TIPSS has been shown to be effective in the treatment of the hepatorenal syndrome. ${ }^{3031}$ The mechanism of this improvement is not entirely clear but the results of this study provide some clues. The reduction in portal pressure gradient by the introduction of TIPSS may be envisaged to increase RBF through the hepatorenal axis and therefore improve renal perfusion, creatinine clearance and sodium excretion.

Ideally, the systemic samples for the measurement of neurohormonal factors should have been collected from the pulmonary artery to avoid the problems of streaming and inadequate mixing. This streaming effect and poor mixing may be responsible for the higher values of ANP found in the renal vein rather than in the right atrium. (ANP is produced in orificium of the coronary sinus and then secreted into the right atrium.) Similarly, the kidneys are important in the production of renin. Higher concentrations of renin are therefore expected in the renal circulation. The finding of higher values of renin in the right atrium in this study may be related to the mixing problem.

The higher cGMP concentration in the systemic circulation probably reflects increased nitric oxide activity because the ANP concentrations were normal. Normal adrenaline and noradrenaline concentrations in these patients may reflect adequate shunt function and the absence of ascites. Notably, higher concentrations of noradrenaline (vasoconstrictor) and cGMP (reflecting nitric oxide activity vasodilator) in the renal circulation may represent the reciprocal role of these substances in the regulation of RBF. Insignificant change in the ANP concentration argues against the change in RBF being the result of a significant alteration in the circulating volume. Similarly, the renin-angiotensin system has not been implicated in the mediation of this phenomenon. These observations suggest that these hormonal factors do not have an important role in modulating the change in $\mathrm{RBF}$ and point to the existence of a hepatorenal axis in the mediation of this phenomenon.

It was therefore somewhat surprising that the concentrations of adrenaline and noradrenaline were not significantly different before and after shunt occlusion. This may either be because of the limit of detectability of the assay used or to the rapid uptake and breakdown of these catecholamines by synaptic monoamine-oxidase inhibitors and catecholamineO-methyl transferases. The problems of streaming and inadequate mixing of blood in the renal vein and the right atrium may be partially responsible for the normal values of adrenaline and noradrenaline observed.

Electrophysiological or pharmacological studies are required for the confirmation of the role of the sympathetic system as an effector arm of this phenomenon. It is also possible that this phenomenon may be mediated by other intrarenal factors described earlier. Further studies are required to ascertain the role of these factors in the mediation of this phenomenon which may be important in the pathogenesis of the hepatorenal syndrome.

The contribution of the reduction in cardiac output following shunt occlusion to the reduction in RBF cannot be disregarded. Occlusion of TIPSS seems to induce a decrease in venous return and, therefore, possibly re-distribution in blood flow. However, the change in cardiac output did not produce any significant haemodynamic disturbance. The transient increase in $\mathrm{RBF}$ between two and four minutes in three patients after inflation of the balloon is difficult to explain but further argues against a significant role of reduction in cardiac output being important in the change in RBF. Unfortunately, in this study we have not measured changes in cardiac output at these time points. The statistical insignificance of the change in mean arterial pressure is unlikely to be because of the number of patients studied in each group as the difference remained inconsequential even when changes in both groups were considered together. Finally, as pointed out earlier, the degree of reduction in cardiac output cannot fully explain the changes in RBF.

In conclusion, we have demonstrated a dramatic reduction in RBF with acute increase in PAG which is compatible with the existence of hepatorenal reflex in man, although other mechanisms may also be contributory. This is a reproducible model which can be used to study this phenomenon further, improve our understanding of the changes in renal circulation in liver disease, thereby providing clues for the development of new treatments.

We acknowledge gratefully the helpful advise from Dr A D Cummings. We are also grateful to Professor M Lee, Dr B C Williams, Mr J J Morton, Mr H Thomas, and Mr N Henderson for hormonal assays.

Parts of this work have been presented in abstract form to the Parts of this work have been presented in abstract form to the
British Society of Gastroenterology (Gut 1994; 35: S9) and to British Society of Gastroenterology (Gut 1994; 35: S9) and to
the American Association for the Study of Liver Diseases (Hepatology 1994; 20: 102A).

1 Baldus WP, Summerskill WHJ, Hunt JC, Maher FT. Renal circulation in cirrhosis: observations based on catheterisation of the renal vein. $\mathcal{f}$ Clin Invest 1964; 43: 1090-7.

2 Sacerdoti D, Bolognesi M, Merkel C, Angeli P, Gatta A. Renal vasoconstriction in cirrhosis evaluated by Doppler ultrasonography. Hepatology 1993; 17: 219-24

3 Kew MC, Varma RR, Williams HS, Brunt PW, Hourigan $\mathrm{KJ}$, Sherlock S. Renal and intrarenal blood flow in cirrhosis of the liver. Lancet 1971; ii: 504-10.

4 Epstein M, Berk DP, Hollenberg NK, Adams DF, Chalmers TC, Abrams HL, et al. Renal failure in patients with cirrhosis. Am f Med 1970; 49: 175-85.

5 Henriksen JH, Ring-Larsen H, Christensen NJ. Hepatic intestinal uptake and release of catecholamines in cirrhosis. Evidence of enhanced hepatic intestinal sympathetic nervous activity. Gut 1987; 28: 1637-42. 6 Ring-Larsen H, Hesse B, Henriksen JH, Christensen NJ. hemodynamics in cirrhosis - plasma norepinephrine conhemodynamics in cirrhosis - plasma norepinephrine concentration, hepatic extra

7 Lang F, Tschernko E, Schulze E, Ottl I, Ritter M, Volkl H, et al. Hepatorenal reflex regulating kidney function. Hepatology 1991; 14: 590-4.

8 Rossle M, Haag K, Ochs A, Sellinger M, Noldge G, Perarnau JM, et al. The transjugular intrahepatic portosystemic stent-shunt procedure for variceal bleeding. N Engl F Med 1994; 330: 165-71

9 Jalan R, Redhead DN, Simpson KJ, Elton RA, Hayes PC. Transjugular intrahepatic portasystemic stent-shunt (TIPSS): long term follow up. $Q \mathcal{F}$ Med 1994; 87:
565-73. 
10 Hayes PC, Terrace D, Peaston I, Bouchier IA, Redhead DN, Brash HM. Computerised system for the continuous measurement of azygos venous blood flow. Gut 1992; 33: 372-4

11 Goldstein DS, Feuerstein G, Izzo JL, Kopin IJ, Keiser HR Validity and reliability of liquid chromatography with electrochemical detection for measuring plasma levels of norepinephrine and epinephrine in man. Life Sci 1981; 28: 467-75.

12 Matthews JNS, Altman DG, Campbell MJ, Royston P. Analysis of serial measurements in medical research. $B M$ Analysis of serial mea

13 Witte MH, Witte CL, Dumont AE. Progress in liver disease: Physiological factors involved in the causation of cirrhotic ascites. Gastroenterology 1971; 61: 742-50.

14 Leiberman FL, Denison EK, Reynolds TB. The relationship of plasma volume portal hypertension, ascites and, renal sodium and water retention in cirrrhosis: the overflow theory of ascites formation. Ann NY Acad Sci 1970; 170: 202-6.

15 Schrier RW, Arroyo V, Bernardi M, Epstein M, Henriksen JH, Rodes J. Peripheral arterial vasodilatation hypothesis: a proposal for the initiation of renal sodium and water retention in cirrhosis. Hepatology 1988; 8: 1151-7.

16 MacGilchrist AJ, Craig KJ, Hayes PC, Cumming AD. Effect of serine protease inhibitor, aprotinin, on sysEffect of serine protease inhibitor, aprotinin, on syswith hepatic cirrhosis and ascites. Clin Sci 1994; 87: with he $329-33$.

17 Rimola A, Gines P, Arroyo V, Camps J, Peres-Ayuso RM, Quintero E, et al. Urinary excretion of 6-ketoprostaglandin $\mathrm{Fl}$, thromboxane $\mathrm{B2}$, and prostaglandin E2 in cirrhosis with ascites; relationship to functional renal failure (hepatorenal syndrome). $\mathcal{f}$ Hepatol 1986; 3: 111-7

18 Moore KP, Taylor GW, Maltby N, Dollery CTD, Williams R. Increased production of cysteinyl leukotrienes in hepatorenal syndrome. $\mathcal{f}$ Hepatol 1990; 11: 262-71.

19 Caramelo C, Fernandex-Gallardo S, Santos JC, Inarrea P, Sanchez-Crespo M, Lopez-Novoa JM, et al. Increased levels of PAF-acether in blood from patients with cirrhosis of the liver. Eur $\mathcal{f}$ Clin Invest 1987; 17: 7-11.
20 Uchihara M, Izumi N, Sato C, Marumo F. Clinical significance of elevated plasma endothelin concentration in patients with cirrhosis. Hepatology 1992; 16: 95-9.

21 Lee FY, Colombato LA, Albillos A, Groszmann RJ. N-nitro$\mathrm{L}$-arginine administration corrects peripheral vasodilatation and systemic capillary hypotension and ameliorates plasma volume expansion and sodium retention in portal hypertensive rats. Hepatology 1993; 17: 84-90.

22 Llach J, Gines P, Arroyo V, Salmeron JM, Gines A, Jiminez $\mathrm{W}$, et al. Effect of dipyridamole on the kidney function in cirrhosis. Hepatology 1993; 17: 59-64.

23 Bosch J, Arroyo V, Betriu A, Mas A, Carrilho F, Rivera F et al. Hepatic hemodynamics and the renin-angiotensinet al. Hepatic hemodynamics and the renin-angiotensin92-9.

24 Moreau R, Cailmail, Gaudin C, Hamon G, Lebrec D. Renal and hemodynamic responses to a novel inhibitor of vasopressin secretion, RU 51599, in rats with cirrhosis [abstract]. $\mathcal{F}$ Hepatol 1994; 21: S7.

25 Gines P, Jiminez W, Arroyo V, Navasa M, Lopez C Tito L, et al. Atrial natriuretic factor in cirrhosis with ascites; plasma levels, splanchnic release and cardiac extraction. Hepatology 1988; 8: 636-42.

26 Barajas L, Powers K, Wang P. Innervation of the renal cortical tubules: a quantitative study. Am $\mathcal{F}$ Physiol 1984; 247: F50-60.

27 DiBona GF. Neural regulation of renal tubular sodium reabsorption and renin secretion: integrative aspects. Clin reabsorption and renin secretion: integrative aspect

28 DiBona GF, Sawin LL. Renal nerve activity in concious rats during volume expansion and depletion. Am $\mathcal{F}$ Physiol during volume expan

29 Solis-Herruzo JA, Duran A, Favela V, Castellano G, Madrid JL, Munoz-Yague MT, et al. Effects of lumbar sympathetic block on kidney function in cirrhotic patients with hepatorenal syndrome. $\mathcal{F}$ Hepatol 1987; 5: 167-73.

30 Ochs A, Rossle M, Haag K, Gerbes A, Morgenroth A Deibert $\mathrm{P}$, et al. TIPS for hepatorenal syndrome [abstract]. Hepatology 1994; 20: 114A.

31 Alam I, Bass NM, LaBerge JM, Ring EJ, Somberg KA Treatment of hepatorenal syndrome with the transjugular intrahepatic portosystemic shunts (TIPS) [abstract]. intrahepatic portosystemic shunt
Gastroenterology 1995; 108: 1024A. 